\title{
No trilho da 'viagem filosófica' de Alexandre Rodrigues Ferreira: uma breve história das suas coleções e sua disseminação
}

\author{
On the trail of Alexandre Rodrigues Ferreira's 'philosophical voyage': \\ a brief history of its collections and their dissemination
}

\author{
Ângela Maria Vieira Domingues (1D \\ Universidade de Lisboa. Lisboa, Portugal
}

\begin{abstract}
Resumo: A 'viagem filosófica' de Alexandre Rodrigues Ferreira é, de longe, a mais intensa e profusamente estudada pela comunidade acadêmica portuguesa e brasileira. Este artigo pretende fazer um ponto de situação em relação à história das coleções e ao modo como este valioso patrimônio foi considerado ao longo do tempo; e destacar como, ainda hoje, continua a ser um espólio importante e válido para as mais diversas áreas científicas. Nesse sentido, proponho, em primeiro lugar, fazer um ponto de situação sobre a origem da coleção documental, considerando os textos e os registros visuais (desenhos, mapas, espécimes naturais, herbários, materiais tridimensionais) e os seus múltiplos destinos; seguidamente, procuro entender como se processou a disseminação deste espólio e de que forma é que a comunidade acadêmica e a sociedade puderam gradualmente aceder aos textos e à iconografia, nomeadamente através de publicações, exposições, plataformas digitais: e, finalmente, pretendo destacar a riqueza dum conjunto documental que continua a permitir leituras múltiplas e olhares renovados não apenas a historiadores, mas também a cientistas das mais diversas áreas. Conjuntamente, eles têm um papel notável na preservação e na disseminação dum patrimônio que, por tanto tempo, ficou oculto, quase esquecido.
\end{abstract}

Palavras-chave: Amazônia colonial. Alexandre Rodrigues Ferreira. Viagem filosófica. Coleções. Disseminação de conhecimento científico.

\begin{abstract}
Alexandre Rodrigues Ferreira's 'philosophical voyage' is by far the most intense and profusely studied voyage by the Portuguese and Brazilian academic community. This article intends to take stock in relation to the history of the collection and the ways in which this valuable heritage was considered over time; and to highlight how, even today, it remains an important and valid collection for the most diverse scientific areas. Therefore, I propose, firstly, to make a situation report on the origins of this collection, considering texts and visual records (drawings, maps, natural specimens, herbariums, three-dimensional materials) and their multiple destinations; then, to understand how this heritage was disseminated and how the academic community and the society were gradually able to access texts and iconography, namely through publications, exhibitions, digital platforms; and, finally, to highlight the richness of a documentary set that continues to allow multiple readings and renewed views not only for historians, but also for scientists from the most diverse areas. Together, they play a notable role in the preservation and dissemination of a heritage that, for so long, was hidden, almost forgotten.
\end{abstract}

Keywords: Colonial Amazon. Alexandre Rodrigues Ferreira. Philosophical voyages. Collections. Dissemination of scientific knowledge.

Domingues, Â. M. V. (2021). No trilho da 'viagem filosófica' de Alexandre Rodrigues Ferreira: uma breve história das suas coleções e sua disseminação. Boletim do Museu Paraense Emílio Goeldi. Ciências Humanas, 16(3), e20200109. doi: 10.1590/2178-2547-BGOELDI-2020-0109 Autora para correspondência: Ângela Maria Vieira Domingues. Universidade de Lisboa. Faculdade de Letras. Alameda da Universidade. Lisboa, Portugal.1600-214 (adomingues@netcabo.pt).

Recebido em 07/09/2020

Aprovado em 09/12/2020

Responsabilidade editorial: Priscila Faulhaber 
A história das ciências é uma das áreas científicas que, especialmente depois dos anos de 1990, vem adquirindo relevância historiográfica e captando a atenção da sociedade, sobretudo quando se centra em temas relacionados com a globalização e a história ambiental'. Contudo, dentro desta área científica tão abrangente, existem assuntos a que os historiadores têm dedicado particular atenção e pelos quais têm revelado uma especial preferência. Um deles é, sem dúvida, o das 'viagens filosóficas' e, entre essas, queremos enfatizar o lugar destacado que a 'viagem filosófica' realizada por Alexandre Rodrigues Ferreira a Pará, Rio Negro, Mato Grosso e Cuiabá, entre 1783 e 1792, tem merecido.

Esta viagem científica decorre num período de enormes transformações, sentidas em Portugal e em nível global, em termos geográficos, geopolíticos, militares e científicos. Destinava-se a contribuir para a renovação do entendimento científico que os vassalos da coroa portuguesa tinham do seu mundo colonial, uma vez que estava em articulação com outras viagens realizadas no mesmo período a Angola, Moçambique e Cabo Verde. Neste projeto científico e político-econômico estruturado em torno duma 'história natural das colônias', o Estado português teve, indiscutivelmente, um papel central e centralizador: na preparação das viagens, no recrutamento e no treino das equipes científicas, no financiamento e na coordenação logística das expedições, na designação das regiões exploradas, na recepção e no controle dos resultados que, na generalidade, se mantiveram, por largo período de tempo, inéditos (Raminelli, 2009; Kantor, 2004; Domingues, 2019).

Este artigo tem como objeto estudar a história do espólio documental produzido pelo naturalista Alexandre Rodrigues Ferreira ao longo da viagem de dez anos pela Amazônia e pelo Mato Grosso; e perceber por que este conjunto de textos, imagens e objetos, constituído nos anos de 1780-1790, continua a ter interesse e a permitir leituras múltiplas e olhares renovados não apenas aos historiadores, mas também a cientistas das mais diversas áreas e ao público em geral.

Quero afirmar, de modo enfático, que esta viagem é, de longe, a mais intensa e profusamente estudada pela comunidade acadêmica portuguesa e brasileira, embora ela não seja a única viagem científica que, nas décadas de 1780 e 1790, tivesse sido financiada, organizada e enviada pelo Estado português às suas conquistas ultramarinas (Simon, 1983; Munteal Filho, 2006; Pataca, 2006; Raminelli, 2009; Domingues, 2019). De fato, esta expedição era um mero, embora relevante, componente de um ambicioso projeto cientííco e político-econômico, coordenado pelo naturalista Domingos Vandelli e pelo jardineiro-botânico Júlio Matiazzi, que corporizava a forma instrumentalizada, pragmática e utilitária de como a ciência era concebida pelo Estado Absolutista português, nomeadamente através do conhecimento produzido e recolhido através de 'viagens filosóficas' enviadas aos domínios ultramarinos (Cardoso, n.d.). Era através dum conhecimento exato da natureza e da sua exploração racional, proporcionados pelo conhecimento científico que adviria das viagens dos naturalistas formados na Universidade de Coimbra pós-reformada (1772), que os teóricos portugueses de Setecentos ligados à tomada de decisões políticas e geoestratégicas pretendiam reabilitar econômica e politicamente o reino e elevá-lo à posição, outrora detida, de potência europeia com prestígio e influência em nível global.

Em primeiro lugar, pretendo fazer um ponto de situação sobre a origem da coleção documental da 'viagem filosófica' - os textos e os registros visuais (desenhos, mapas, espécimes naturais, herbários, materiais tridimensionais) - e os seus múltiplos destinos. Uma das questões que se me afigura central quando penso neste assunto relaciona-se com a riqueza e a diversidade do patrimônio cultural e científico

Sobre estas transformações no mundo ibérico e atlântico e sobre as novas perspectivas da ciência ibérica, ver Sánchez (2019) e Manning (2016). 
produzido durante a viagem e de como o passar do tempo não desconsiderou muitas das atividades relacionadas com a recoleção, a observação e o registro científico feitos pelo naturalista. Esta questão prende-se intimamente com a produção e a conservação dos documentos produzidos por Ferreira e pela sua equipe (textos, imagens, objetos), mas também com a existência de instrumentos de busca eficientes (inventários, catálogos) e outros instrumentos de 'controle e de preservação da memória institucional' dos materiais depositados em organismos de ciência e de saber (por exemplo, museus, bibliotecas e arquivos) que nos permitem - aos que hoje em dia fazemos ciência aceder eficazmente à informação produzida por Alexandre Rodrigues Ferreira e pela sua equipe nos anos de 17801790.

Sabe-se que logo após a morte de Alexandre Rodrigues Ferreira, a 23 de abril de 1815, o espólio foi entregue por sua mulher, D. Germana Pereira de Queiroz Ferreira, e foi depositado nos arquivos do Real Gabinete de História Natural e Jardim Botânico da Ajuda à guarda do botânico Félix de Avelar Brotero. $O$ inventário, feito por Antônio de Azevedo Coutinho, datado de 5 de julho desse ano, registrava 57 obras atribuídas à 'viagem filosófica', entre memórias, notícias, diários de viagem, prospectos, relações, observações gerais, descrições; 17 não pertenciam à viagem; e 29 não tinham nome, mas podiam ser atribuíveis a Ferreira².
Alguns anos mais tarde, em 1838, este núcleo documental foi transferido para a Academia Real das Ciências de Lisboa. Reconhecendo que o acervo, constituído por 22 maços de textos e por seis volumes e um maço com desenhos e plantas, era "do maior interesse scientifico e para o Império do Brasil ainda a este une outros muito importantes, econômica e politicamente considerados" (Sá, 1838), Manuel José Maria da Costa e Sá, sócio correspondente e responsável pela comissão avaliadora da Academia Real das Ciências de Lisboa, valorizava o núcleo documental ao mesmo tempo que destacava o papel do Estado português como financiador, organizador e destinatário da 'viagem filosófica', quando afirmava que: "as memórias e papéis, de que se trata, não são propriedade sua [da Academia de Ciências de Lisboa], sim do Estado; por onde para a publicação deles intentar, tem de fazer deles sempre uma consulta ao Governo de Sua Majestade" (Sá, 1840, pp. 511-513).

Alguns dos manuscritos mantiveram-se à guarda da Academia e nos arquivos da Secretaria de Estado da Marinha e Negócios Ultramarinos (maioritariamente reunidos no Arquivo Histórico Ultramarino). As remessas de 'produtos naturais e industriais', para além de se reunirem no 'complexo museológico' da Ajuda, teriam começado a ser enviadas para o Museu de História Natural da Universidade de Coimbra provavelmente ainda antes de $1806^{3}$. Contudo, é importante referir que,

2 O catálogo então produzido intitulava-se "Catálogo geral dos papéis pertencentes à viagem do Dr. Alexandre Rodrigues Ferreira aos Estados do Brasil, que me foram entregues por ordem do Ilmo. e Exmo. Sr. Visconde de Santarém" e era assinado por Félix de Avelar Brotero. Uma notícia com base neste inventário com o nome de "Notícia dos escriptos do Dr. Alexandre Rodrigues Ferreira", seguida por um "Additamento" de Manuel José Maria da Costa e Sá, foi publicada na Revista do Instituto Histórico e Geográfico Brasileiro (Sá, 1840, pp. 503-513). Em 1876, Alfredo do Vale Cabral fez novos inventários das obras depositadas na Biblioteca Nacional, no Rio de Janeiro. As "Notícias das obras manuscritas e inéditas relativas à viagem philosophica do Dr. Alexandre Rodrigues Ferreira, pelas capitanias do Grão-Pará, Rio Negro, Mato Grosso e Cuyabá (1783-92)” foram publicadas nos Anais da Biblioteca Nacional (Annaes da Bibliotheca Nacional do Rio de Janeiro, 1876-1877 [1876], pp. 103-129, 222-247, 1876-1877 [1877], pp. 192-198, 1877-1878 [1877], pp. 54-67, 324-354). Deve-se salientar o notável trabalho de disseminação do espólio de Alexandre Rodrigues Ferreira, que tem sido continuado recentemente através de várias plataformas eletrônicas nas quais se disseminam documentos textuais, desenhos e ilustrações da viagem filosófica, a exemplo do que tem sido feito pela Biblioteca Nacional Digital (ver Sodré, n.d.); pela Biblioteca Digital Luso-Brasileira (n.d.); pela Brasiliana (ver Equipe da Biblioteca Nacional, n.d.); e ainda pela História Natural Digital/MUHNAC (ver Museu Nacional de História Natural e da Ciência, n.d.). Sobre a história do espólio e as várias iniciativas para a publicação dos textos, ver S. Rodrigues (2010).

3 Esta instituição teve a sua origem nos espécimes trazidos da Itália por Domingos Vandelli e gradualmente foi incorporando materiais enviados de Lisboa e de outros locais, alguns deles relacionados com as 'viagens filosóficas' (Munteal Filho, 2006; Casaleiro \& Pereira, 2018; Cantinho, 2010, p. 4).

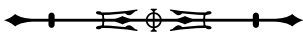


logo após 1807 e com as alterações políticas e institucionais associadas à transferência da corte para o Brasil e à permanência do exército de Junot em Lisboa por altura das Guerras Peninsulares, se acentuou a disseminação deste acervo por várias entidades públicas e particulares. Esta dispersão é contada por vários autores através de episódios, alguns deles dramáticos, relacionados, por exemplo, com 'espólios de guerra', com transferências de local e de país ou com histórias rocambolescas de 'intervenções providenciais e resgates salvadores'. De entre estes episódios, faça-se uma menção ao papel incontornável que Antônio de Meneses Vasconcellos Drumond, ministro plenipotenciário do Brasil em Portugal entre 1839 e 1853, teve enquanto responsável pelo envio da uma parte substantiva do espólio de Ferreira para o Rio de Janeiro ${ }^{4}$.

Creio que, acima de tudo, é importante reter que a história da coleção documental - textual e visual - da 'viagem filosófica' (e da sua dispersão) é, pois, intrigante, complexa e fascinante, quase comparável à trama dum romance policial. Um dos episódios repetidamente contados pela historiografia é, como já fiz alusão, o do 'espólio ou saque de guerra' associado à atuação de Étienne Geoffroy de Saint-Hilaire. De fato, durante a Guerra Peninsular (1807-1814), o naturalista francês, que acompanhou o general Jean-Andoche Junot durante a primeira invasão franco-espanhola a Portugal, demonstrou um interesse particular pelo espólio do naturalista português. Saint-Hilaire remeteu para a capital francesa uma parte considerável do material existente no Real Gabinete da Ajuda: manuscritos, desenhos, produções naturais, que foram parcialmente devolvidos a Portugal em $1815^{5}$. Este acontecimento é, por vezes, considerado como o início da destruição da integridade do acervo de Ferreira e o responsável pelo declínio moral e físico do naturalista. Contudo, uma versão bastante lúcida e fundamentada deste episódio é contraposta por Arthur Cezar Ferreira Reis que, ao invés de pôr a tônica na espoliação e no saque de manuscritos originais e de espécimes, argumenta que Saint-Hilaire teria sido extremamente seletivo e criterioso na escolha dos materiais enviados para Paris. Com autorização das entidades locais lisboetas e com base em inventário existente, teria enviado uma 'porção mínima' das peças que, naquela data, ainda estavam encaixotadas (Reis, 1971).

Parece-me que esta questão pode ainda ser abordada por um outro ângulo. Ao contrário do que alguns autores têm sublinhado, sou de opinião que essa curiosidade de Étienne Geoffroy de SaintHilaire pelas produções naturais relacionadas com a 'viagem filosófica', embora, de fato, se direcionasse prioritariamente para as coleções do Real Gabinete da Ajuda e para o material de Alexandre Rodrigues Ferreira, era mais abrangente. Incidia sobre todo o território americano e dado que, neste caso concreto, se estava a considerar Portugal e a informação sobre os seus domínios coloniais, esta curiosidade centrar-se-ia especificamente sobre a América portuguesa, direcionada para territórios que eram familiares aos meios acadêmicos franceses, particularmente depois da missão geodésica e astronômica enviada ao Peru pela Academia de Ciências de Paris (1735-1743) e da subsequente viagem de Charles-Marie de La Condamine pela bacia hidrográfica amazônica (1743). Esta curiosidade 'americana' teria levado Geoffroy de Saint-Hilaire a percorrer, a horas inusitadas, as livrarias dos conventos lisboetas e a inquirir (e provavelmente em alguns casos a 'requisitar' de forma

\footnotetext{
4 É Alfredo do Valle Cabral quem reconhece "que as numerosas obras que o Dr. Ferreira escreveu e coligiu concernentes à sua importante viagem científica se acham em sua quase totalidade nesta Corte [do Rio de Janeiro]. Elas vieram há bem poucos anos para o Brasil. . .A história da vinda desses manuscritos e de sua completa debandada é bem curiosa" (Cabral, 1952, p. 41).

5 Falcão (1970, p. 190) afirma que foram devolvidos apenas os manuscritos (ver também S. Rodrigues, 2010, pp. 29-30).
}

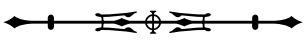


permanente) livros que as bibliotecas conventuais tinham sobre a colônia brasileira6 ${ }^{\text {. }}$

Esta questão aponta, na minha opinião, para o conhecimento incipiente que, até inícios de oitocentos, os europeus tinham sobre esta parte do Novo Mundo - até o início do século XIX tão pouco conhecida - que era a América portuguesa. $O$ interesse que agora demonstravam não era novo e justificava-se simultaneamente por questões de natureza econômica, associadas ao reconhecimento e à extração de matérias-primas e recursos naturais valiosos provenientes das colônias sul-americanas; por aspectos de natureza científica, relacionados com a evolução da ciência europeia e com a vontade de ordenar, classificar e nomear de acordo com os sistemas taxonômicos, de que o lineano era apenas um, todo o mundo conhecido dos europeus, bem como do prestígio e do lucro que adviriam se houvesse uma precedência francesa; e pressupunha, igualmente, interesses geopolíticos e hegemônicos, correlacionados com a concorrência entre potências europeias dominantes em nível global. A Inglaterra e a França protagonizam incontestavelmente os projetos imperiais de dominação política, econômica, científica sobre a América do Sul e sobre os territórios ibéricos (Domingues, 2011, pp. 35-51).

Mas, regressando às coleções de Alexandre Rodrigues Ferreira, entre as entidades que detêm ou receberam espólio proveniente da 'viagem filosófica', mencionem-se como sendo das mais relevantes: o Museu Bocage (atual Museu Nacional de História Natural e da Ciência da Universidade de Lisboa - MUHNAC/UL) e - Museu Maynense (da Academia de Ciências de Lisboa - ACL), o Arquivo Histórico Ultramarino/Direção-Geral do Livro, dos Arquivos e das Bibliotecas (AHU/DGLAB), em Lisboa; o Museu Antropológico da Universidade de Coimbra; a Fundação Biblioteca Nacional (FBN), o Arquivo
Nacional (AN), o Instituto Histórico e Geográfico Brasileiro (IHGB) e o Museu Nacional (MN), no Rio de Janeiro. E, ainda, o Arquivo Público do Estado de Mato Grosso, em Cuiabá; o Arquivo Público do Estado do Pará, em Belém; e o Musée de l'Homme/Museum National d'Histoire Naturelle (MNHM), em Paris (J. Silva, 1994, p. 295; Areia et al., 2013).

Seguidamente, quando se trata deste importante espólio, existe uma outra questão que me parece ser relevante e que se prende com a disseminação da coleção documental. Ou seja, como e a partir de quando os resultados obtidos pela 'viagem filosófica' passaram a ser facilmente utilizados pela comunidade acadêmica, tornando-se também acessíveis à leitura e à visualização pela sociedade? Parece-nos que esta questão está indubitavelmente relacionada com a publicação e a exposição dos documentos produzidos por Ferreira.

No que diz respeito à publicação dos manuscritos, não deixa de ser interessante ter em consideração que, por volta de 1838, houve, por parte da ACL, uma tentativa de publicar seletivamente os textos que Manuel José Maria da Costa e Sá, como responsável pela avaliação desencadeada por esta instituição, considerasse mais relevantes. Não obstante, a obra de Ferreira permaneceria inédita até que o IHGB atentou que a sua disseminação era de interesse nacional. E demonstrou esse empenho com a publicação, logo no segundo volume da Revista do IHGB, do panegirico do Dr. Alexandre Rodrigues Ferreira (Pontes, 1840, pp. 499-502). Quanto ao primeiro texto do naturalista a ser editado, ele foi "Propriedade e posse das terras do Cabo do Norte pela coroa de Portugal" (Ferreira, 1841, pp. 389-421), seguido de "Gruta do Inferno" (Ferreira, 1863, pp. 363-367), de "Viagem à gruta das Onças" (Ferreira, 1849, pp. 87-95) e, finalmente, do "Diário da viagem filosófica ao Rio Negro", cuja publicação

\footnotetext{
6 É José Liberato Freire de Carvalho quem relata o episódio curioso da visita de Étienne Geoffroy de Saint-Hilaire ao convento de S. Vicente e à sua livraria, considerada como uma das 'principais de Lisboa', como parte da missão que lhe tinha sido confiada pelo imperador Napoleão Bonaparte: levar os livros que julgasse mais interessantes, nomeadamente os que incidissem sobre o Brasil, para Paris (J. Carvalho, 1855, pp. 56-58).
}

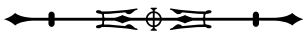


se iniciou em 1885 e se foi sucedendo nos volumes seguintes ${ }^{7}$. A edição da "Viagem filosófica ao Rio Negro" num único volume impresso teria que esperar até 1983 (Ferreira, 1983) e foi seguida, em 2007, duma segunda edição revista e organizada por Francisco Jorge dos Santos, Auxiliomar Silva Ugarte e Mateus Coimbra de Oliveira (ver Ferreira, 2007b).

No que diz respeito às memórias de antropologia, botânica e zoologia, foram impressas pelo Conselho Federal de Cultura (CFC), nos anos de 1972 e 1974 (Ferreira, 1972, 1974), como parte dum plano mais abrangente de divulgação, ordenada e anotada, da 'viagem filosófica'. Nesta mesma ocasião (1971), o CFC publicava também parte substantiva do material iconográfico relativo à geografia, à antropologia e à zoologia em dois magníficos volumes antecedidos dum sucinto, mas elucidativo, prefácio de Arthur Cezar Ferreira Reis (ver Ferreira, 1971).

Em 2002, a Kapa Editorial iniciava a "maior coleção já publicada da obra de Alexandre Rodrigues Ferreira", reunindo num único projeto a edição de textos e desenhos dispersos por bibliotecas e arquivos portugueses e brasileiros e as reproduções de objetos conservados em museus franceses e portugueses, comentadas por especialistas de várias áreas (J. Silva, 2006, pp. 135-143; Ferreira, 2007a).

Atualmente, podemos aceder a muita informação relacionada com a 'viagem filosófica' através de uma série de plataformas digitais que disponibilizam reproduções de textos, desenhos e objetos. Com o apoio mecenático de fundações privadas ou com verbas públicas, a FBN e o MN têm vindo a restaurar, encadernar, fotografar, microfilmar e digitalizar os 191 textos manuscritos e os 1.180 desenhos que constituem a Coleção Alexandre Rodrigues Ferreira ${ }^{8}$. Paralelamente, esta coleção é disseminada através do portal Brasiliana Iconográfica, um projeto que pretende transformar-se num museu virtual destinado a tornar acessível a um público amplo e internacional os estudos, publicações e referências visuais que digam respeito à história e à cultura do Brasil entre os séculos XVI e XX. Neles, a Coleção ocupa lugar de destaque. Em 2010, Ano Internacional da Biodiversidade, a Coleção Alexandre Rodrigues Ferreira obteve o registro de 'memória do mundo' da UNESCO, um reconhecimento da sua importância para o conhecimento, o estudo e a conservação do ambiente, que sublinha a necessidade da sua preservação.

Aparentemente, esta dispersão dos materiais e a demora na impressão dos manuscritos, que marcaram a história atribulada da coleção por um período considerável de tempo, parecem estar em contradição com o propalado interesse que o naturalista Ferreira e a 'viagem filosófica' despertaram entre a comunidade de cientistas. Devemos, contudo, clarificar que não foi preciso chegar até os dias de hoje para que se reconhecesse que os relatos, os diários de viagem, as memórias zoológicas, antropológicas, botânicas, os mapas populacionais e agrícolas, os tratados produzidos pelo naturalista são imprescindíveis e incontornáveis para conhecer e estudar questões de importância para a Amazônia e para o ambiente, a natureza, as comunidades caboclas e indígenas. Dentre estas questões que têm ocupado um lugar cada vez mais central na investigação científica, aluda-se, por exemplo, aos processos transformadores que a Amazônia colonial conheceu no período pós-pombalino; ao 'universo científico' das Luzes em Portugal; às relações hierárquicas do reino com o Estado do Grão-Pará em nível ideológico, geopolítico, institucional-administrativo, econômico, científico; à fauna e à flora brasileiras, com relevância dada a algumas espécies extintas ou ameaçadas de extinção; ou à longa e perigosa aventura que foi a progressão, por um período de dez anos, pelos rios amazônicos dum grupo de homens que tinha nascido e se tinha formado em locais tão distantes e tão pouco familiares dos que então percorriam.

7 diário foi editado ao longo de vários volumes da RIHGB, a saber: Ferreira (1885, pp. 1-234,1886, pp. 123-288, 1887, pp. 11-141, 1888, pp. 5-166).

8 Biblioteca Nacional Digital (n.d.) e Brasiliana Iconográfica (ver Equipe da Biblioteca Nacional, n.d.).

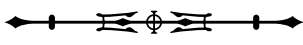


A breve panorâmica traçada em relação aos textos pode, de algum modo, ser transposta para os fascinantes e visualmente exuberantes e multicoloridos desenhos científicos; ou em relação às produções naturais enviadas vivas ou dissecadas e secas e aos objetos tridimensionais, considerados, juntamente com os documentos textuais e iconográficos, como parte integrante da viagem (Sá, 1840, p. 511). As representações da natureza e da humanidade amazônicas - reveladas nas descrições de Ferreira, nas imagens de Joaquim José Codina e José Joaquim Freire, no trabalho de recolha de espécimes vegetais, sementes e constituição de herbários pelo jardineiro-botânico Agostinho Joaquim do Cabo, mas igualmente nos espécimes conservados pelos índios Cipriano de Souza e José da Silva - permaneceram, por largo período, desconhecidas do público que teve acesso às primeiras impressões das aguarelas e desenhos de Codina, Freire e Giuseppe Antônio Landi, em 1971 (Ferreira, 1971). De igual modo, noto que, na generalidade, tinham permanecido afastados dos expositores de gabinetes e museus os artefatos recolhidos e enviados pelo naturalista e pela sua equipe até que as comemorações dos 200 anos da viagem conferissem a muitas das peças o lugar de visibilidade e destaque que lhe era devido; tal como só muito recentemente o herbário de Alexandre Rodrigues Ferreira, constituído por cerca de 1.260 espécimes vegetais, ficou inventariado, digitalizado e, assim, disponível à comunidade científica ${ }^{10}$. O valor histórico e científico deste herbário fica mais claro quando consideramos que alguns dos exemplares são considerados espécimes-tipo que servem de referência à descrição da espécie para a ciência e que outros são espécies novas que, até o presente, nunca foram descritas.

Quero agora clarificar que têm sido estes textos, imagens, objetos e mapas que, através das ações mais variadas e visando objetivos e públicos-alvo os mais diversos, têm sido estudados não apenas por historiadores, mas por cientistas de outras áreas. Pretender enunciar exaustivamente as produções acadêmicas que se têm inspirado na obra de Alexandre Rodrigues Ferreira revelase uma tarefa difícil, senão impossível, porque resultaria desatualizada. E isso porque historiadores, antropólogos, filólogos, etnomuseólogos, diplomatas, cientistas naturais, ambientalistas, agrônomos, editores, fotógrafos, sobretudo após os ensaios pioneiros e críticos de Emílio Goeldi (1895), têm produzido obra sobre a 'viagem filosófica' e contribuem ativamente para recuperar, conservar, estudar com olhares constantemente renovados e disseminar junto da sociedade este patrimônio que, por um período tão longo, ficou oculto, quase esquecido.

A potencialidade dos documentos é, pois, múltipla e a perspectiva de análise é inovadora, por vezes surpreendente. O espólio continua a ser reinterpretado e lido em função da nossa curiosidade científica contemporânea e renovase em função de novas perspectivas e metodologias, correspondendo, assim, a interesses institucionais, individuais e de equipes de projetos. Dentre estas 'novas perspectivas', que são muitas vezes resultantes de trabalhos acadêmicos, citem-se como exemplos: a análise às moléculas da cor derivadas da utilização de urucu, crajiru de origem orgânica e ocre de origem inorgânica nas máscaras dos índios Yurupixuna recolhidas por Ferreira (Carapito, 2014); a

\footnotetext{
9 Refira-se, ainda, o papel relevante que a Editorial Kapa teve, desde 2002, na disseminação sistemática, através da publicação de livros que fazem a reprodução fotográfica dos documentos sobreviventes da 'viagem filosófica', à Amazônia; e dos catálogos de duas grandes exposições realizadas por altura das comemorações do $2^{\circ}$ centenário da viagem (ver Areia et al., 1991; Dias, 1992). A este esforço de inventariação e disseminação da informação proveniente da viagem filosófica, deve-se ainda acrescentar o catálogo publicado por R. Carvalho (2000), "O material etnográfico do Museu Maynense da Academia de Ciências de Lisboa"; as menções sucintas, mas indicadoras da importância da coleção (ver Museu Maynense, 2016); e o catálogo de David Felismino - ver Felismino (2014) a respeito dos materiais da viagem sobreviventes nas coleções da antiga Casa Real portuguesa. Dentre os recursos eletrônicos, o mais relevante está em Brasiliana Iconográfica (n.d.).

10 O herbário encontra-se no Departamento de Botânica do MUNHNAC (ver Herbário de Alexandre Rodrigues Ferreira (sec. XVIII-XIX), n.d.).
}

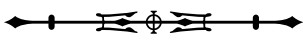


importância da fixação do desenho científico na ciência no período posterior a Lineu, tomando por base os animais desenhados por Codina e Freire (Tapadas, 2006); o levantamento sistemático, através de diários e memórias, das plantas do Norte e Centro-Oeste brasileiros, com aplicação e utilidade na agricultura, medicina, tinturaria (P. Oliveira, 2008). Trabalhos como estes refletem um amplo espectro no percurso e na maturidade científica dos acadêmicos que se debruçam sobre o espólio, tanto mais que nos confrontamos com inúmeras teses e dissertações de livre-docência, doutoramento, mestrado, pós-graduação sobre Ferreira e a 'viagem filosófica', em universidades portuguesas e brasileiras.

Não esqueço ainda, obviamente, as influências que são ditadas pelo tempo e pelas modas, pelas correntes historiográficas que influenciam os vários autores nas escolhas de temas ou pelos períodos das 'comemorações'. Estas podem facilmente ser associadas à intensificação dos esforços institucionais para preservar e restaurar os artefatos museológicos, ao aumento de publicações (fontes e estudos) e à realização de exposições, como se depreenderá do que já foi mencionado.

Essa multiplicidade de interesses e perspectivas desdobra-se em interpretações que buscam, por exemplo, entender a viagem globalmente, valorizando-a enquanto 'acontecimento destacado' entre as políticas imperiais do Estado português ao longo da segunda metade de Setecentos (Goeldi, 1895; Correia Filho, 1939; Cunha, 1991; Costa \& Diener, 2010); que pretendem estudar a viagem e a presença colonial 'luso-brasileira' numa área geográfica particular, como é o caso de Mato Grosso, da ilha de Marajó ou da bacia hidrográfica amazônica (Costa, 2001, pp. 993-1014; Pataca, 2005, pp. 149-169; Raminelli, 1998; Domingues, 1992; Lamarca, 2015, Carvalho Júnior \& Noronha, 2011; Guedes, 2013); ou então que a consideram como um episódio emblemático das inúmeras alterações intelectuais e científicas ocorridas em Portugal ao longo da segunda metade do século XVIII, com especial impacto nos espaços coloniais portugueses considerados como 'periféricos' (Simon, 1983; Pataca, 2006; Raminelli, 2009); ou ainda que valorizam especificidades regionais e temáticas, de que, sem dúvida, as fronteiras geográficas coloniais, a geopolítica e a diplomacia, o ordenamento do território colonial, as comunidades indígenas, o ambiente, a saúde, a antropologia, a iconografia ocupam posição destacada (Domingues, 1991; Lopes, 1998, Raminelli \& B. Silva, 2014; Coelho, 2000; Carvalho Júnior, 2000; Pataca, 2001, 2015, 2018; Faria, 2001; B. Silva, 2013; Abreu, 2007; Campos, 2015; B. Rodrigues, 2017; Verran, 2006).

Por vezes, as perspectivas de análise propõem a comparação da 'viagem filosófica' com outras viagens científicas organizadas por Espanha aos seus espaços coloniais, nomeadamente com a viagem de Alexander von Humboldt; ou com as políticas científicas dos países europeus em relação à América portuguesa e espanhola, com especial destaque para a relação entre os países ibéricos e as colônias americanas durante um período de profundas transformações, a saber: o das reformas ditas 'pombalinas' e 'borbônicas', tal como foram aplicadas nas zonas de fronteira e na Amazônia 'luso-brasileira' e 'hispano-peruana' (Safier, 2007; Tavares, 2014; Rodríguez García, 2015; T. Oliveira, 2018; Sala Catalá, 1992).

Perante a constatação de que existem tantos estudos sobre a viagem de Alexandre Rodrigues Ferreira, organizados em função de interesses e perspectivas historiográficas ou temáticas tão diversificadas e motivantes, uma pergunta lógica que importará fazer é a seguinte: se a 'viagem filosófica' ocupou (e continua a ocupar), de forma tão intensa e por período tão longo, esta centralidade que lhe é reconhecida na produção historiográfica portuguesa e brasileira, então quais serão os novos caminhos a seguir na exploração deste espólio?

Provavelmente um aspecto que, até ao momento, tem sido menos explorado nestes sempre renovados estudos historiográficos sobre a viagem científica diga respeito aos colaboradores da expedição, entendidos de uma forma bem mais abrangente e que, consequentemente, não se limita apenas aos elementos da equipe. Embora esta categoria 
analítica seja relativamente recente, ela não é propriamente uma novidade enquanto um dos temas preferidos pelos atuais historiadores da ciência ibérica. Os estudos de, entre outros, Candiani (2017), Wendt (2016), Murphy (2011), Barrera Osorio (2008, 2010), Sánchez (2019), Antunes et al. (2019) e Schaffer et al. (2009) para os impérios coloniais ibéricos e para o mundo atlântico, abrangendo um larguíssimo período, que vai desde o século XVI ao século XIX, mostram, de forma clara, como o conhecimento empírico das populações locais influenciou a cultura científica 'ocidental' de acordo com um processo de transferência de saberes que se encontra marcado pela circularidade: da Europa para a América para a Europa, incorporando o oceano Atlântico enquanto objeto válido e transversal de estudos científicos e de saberes empíricos.

É inegável que, no que diz respeito à viagem filosófica, até período recente, a maior parte dos estudos históricos deu destaque, de modo quase inevitável, às múltiplas atividades do naturalista Ferreira, aos desenhos de Codina e Freire, aos herbários e às sementes recolhidas por Cabo, à participação pontual de Landi. Assim foi, durante algum tempo, entendida a viagem filosófica. Assim foram interpretadas as suas coleções documentais, como resultado persistente do trabalho dum grupo restrito de homens com uma formação 'científica' e 'técnica-artística' de matriz europeia 'ocidental'. E, de alguma forma, esta historiografia tendeu a secundarizar, ou até mesmo a esquecer, outros personagens que contribuíram para que a viagem tivesse acontecido: que foram um apoio funcional e logístico imprescindível; que estiveram na origem do processo de seleção, recolha e preservação de espécimes; que prestaram depoimentos orais ou escritos sobre matérias em que eram especialistas e sabedores. Esta vertente dos colaboradores 'formais/nomeados' e 'informais/anônimos' da viagem filosófica começa agora a ser estudada, nomeadamente por Patrícia Alves-Melo e Ângela Domingues. Em artigo sobre a circularidade de saberes existente na construção do conhecimento científico setecentista sobre o mundo amazônico em Portugal, Domingues \& Alves-Melo (2021) defendem que, embora a nossa atenção tenda, provavelmente, a valorizar a colaboração indígena - e o sempre apaixonante processo de trocas culturais e de transferências de conhecimentos entre o naturalista e os nativos -, o universo das redes de saberes e das práticas colaborativas que se estabeleceu na Amazônia em Setecentos tem que considerar a existência de 'várias camadas de informação' e de vários 'saberes'. Se todos foram reconhecidos como válidos, percecionamos também que se encontram utilizados e valorizados de modo diferente nos escritos do naturalista.

As autoras constataram que, apesar de haver bastas referências às atividades ou aos saberes destes indivíduos ou grupos nos diários de viagem, nas memórias científicas, nos ofícios dirigidos por Ferreira aos agentes da coroa, muitos destes colaboradores integravam uma massa indistinta, subalterna, silenciada, anônima, que corporizava os saberes considerados 'tradicionais', 'do vulgo', dos indígenas e das populações caboclas que habitavam as margens dos rios amazônicos e mato-grossenses. Este é o caso de guias, remeiros, línguas, soldados de escolta, moradores das zonas ribeirinhas, que, embora sendo considerados imprescindíveis para a progressão da expedição e para a sobrevivência dos expedicionários nos sertões do Norte e do Centro-Oeste brasileiro, não eram expressamente nomeados nos escritos do naturalista. Contudo, o estudo desenvolvido mostra que houve casos em que foi possível atribuir-lhes um nome e associá-los a funções concretas e a saberes específicos; e, assim, quase se pode dar-lhes um rosto. Este é o caso dos índios preparadores Cipriano de Souza e José da Silva, que tiveram um papel incontornável na recoleção, conservação e acondicionamento das espécies naturais. Tendo sido recrutados logo em 1783 , foram uma presença constante na equipe do naturalista ao longo do seu percurso pelas capitanias do Pará, Rio Negro, Mato Grosso e Cuiabá.

Desta rede de colaboradores da viagem filosófica fazem ainda parte, embora ocupando outra posição que se beneficia do destaque conferido ao conhecimento acadêmico e erudito, à 'autoridade científica', ao 'universo' 
constituído pelos 'pares' formados nas universidades e academias militares -, o cirurgião Antônio José de Araújo Braga, os matemáticos-astrônomos e engenheiroscartógrafos que integravam as partidas de demarcações de limites na década de 1780-1790, o naturalista, desenhador, arquiteto e senhor de engenho Giuseppe Antônio Landi. De fato, Ferreira ter-se-ia cruzado repetidas vezes com eles durante o seu périplo pelos rios amazônicos e mato-grossenses, e com eles teria trocado informações, posteriormente integradas nos textos que produziu ${ }^{11}$. Contrariamente ao que acontecia com indígenas, caboclos e populações ribeirinhas, as contribuições dos indivíduos que Ferreira reconhecia como pares foram valorizadas, e a menção aos nomes dos seus autores é claramente inscrita nos diários e nas memórias científicas do naturalista.

Em suma, as autoras procuraram evidenciar que o espólio de Ferreira é o resultado complexo não apenas das suas observações e da sua experiência em viagem, nem que tampouco dependeu exclusivamente da aquisição de técnicas e de saberes teóricos-científicos e eruditos adquiridos durante a sua formação e treino na Universidade de Coimbra ou no complexo museológico da Ajuda. Mas pressupôs igualmente a existência de práticas colaborativas que o naturalista estabeleceu com os seus pares ao longo da viagem; tal como dependeu de informações provenientes de meios que não eram exclusivamente acadêmicos, relacionados com os saberes vulgares e com transferências culturais entre comunidades e indivíduos.

De acordo com esta perspectiva ainda em desenvolvimento, os colaboradores de Ferreira encontravam-se divididos pelo nascimento e raça, pela educação e formação, pela riqueza e estatuto social, pelo acesso e relações que detinham o poder - fosse este poder personificado por Martinho de Melo e Castro, secretário de Estado da Marinha e Negócios Ultramarinos, ou pelos governadores e capitães-generais do Estado do Grão-Pará e das capitanias, cujas decisões eram contundentes em relação aos destinos e às prioridades da expedição e dos viajantes ou ainda por Domingos Vandelli, diretor do Jardim Botânico da Ajuda (Brigola, 2004). Esses colaboradores da viagem filosófica identificavam-se, de alguma forma, num saber coletivo específico ao 'grupo' socioprofissional ou étnico a que pertenciam, fosse este o dos nativos ameríndios, o dos 'criollos' e dos saberes práticos, ou o dos eruditos e acadêmicos com acesso à cultura científica e ao 'saber institucional científico' ministrado em universidades e academias. Contudo, esses indivíduos faziam parte, naquele preciso momento, do mundo colonial americano português e trocavam informação e partilhavam da experiência que era viver na Amazônia e no Mato Grosso nos anos de 17801790. Os seus trajetos individuais cruzaram-se histórica e funcionalmente no mesmo tempo e espaço geográfico, embora a partir de posições e experiências diferentes, que dependiam das relações de socialidade e profissionais ou das hierarquias de dependência e subalternidade determinantes da sua posição nesta sociedade colonial de Antigo Regime (Sanjad, 2007; Domingues \& Alves-Melo, 2021).

A ausência historiográfica de muitos destes indivíduos é, em alguns casos, explicada pelo silêncio e pela omissão dos textos de Ferreira sobre estas colaborações. Mas em outros casos, é igualmente determinada pela forma como nós, cientistas contemporâneos que (re)lemos Ferreira, questionamos os documentos, porque estamos habituados a direcionar a nossa atenção para os personagens centrais dessa história em função de lógicas eurocêntricas.

Within the historiography of science, however, this
hegemonic centre-periphery model is fast being replaced by
one much more multidirectional, in which the accumulation
of knowledge occurs through multi-dimensional circulations
in the world, resulting in a 'renegotiation' of the centre
and a challenge to its universalism (McOuat, 2017, p. 82).

\footnotetext{
11 Raminelli (1998, p. 5) indica pelo menos a menção aos relatos de viagem de origem administrativa que seriam acessíveis ao naturalista, da autoria de Teodósio Constantino de Chermont (1741-1819), José Antônio Landi (1713-1791), Manuel da Gama Lobo d'Almada (17---1799), mas podemos acrescentar também os nomes de Antônio Pires da Silva Ponte Leme (1757-1806), Ricardo Franco de Almeida Serra (1748-1809), Antônio José de Araújo Braga.
} 
Por isso, creio que repensar estas colaborações de acordo com modelos menos fechados de 'geopolítica do conhecimento', e com noções menos tradicionais de centro/periferias, exploração/conquista, colonialismo/ imperialismo, talvez tenha o mérito de nos reposicionar face a uma história que considera, por exemplo, não apenas as relações hierárquicas de subordinação existentes entre as metrópoles peninsulares e as suas colônias ultramarinas, mas que observa igualmente outras práticas e trocas de saberes; e outras perspectivas nas relações de subordinação e inferioridade que existiram entre os reinos peninsulares católicos e absolutistas, conotados com a 'leyenda negra', e os centros europeus do Norte, que tradicionalmente se consideravam como dominantes e superiores quando se comparavam com os países do Sul, mesmo (ou sobretudo) quando o assunto era ciência e produção científica ${ }^{12}$.

$\bigcirc$ que, neste momento, quero clarificar é que a proposta de refletir sobre estes conceitos no que diz respeito à história da ciência e dos espaços imperiais portugueses pode levar-nos ao reconhecimento de que a produção de ciência não estava confinada a Portugal, à Europa e às instituições acadêmicas reinóis ou europeias. E que os novos caminhos da história da ciência reconhecem que nas colônias - e, neste caso concreto, na Amazônia durante a segunda metade de Setecentos - também se produzia ciência e informação com interesse científico; e que as populações nativas e 'criollas' 'periféricas' participavam ativamente num processo que é bastante mais abrangente do que o que habitualmente consideramos quando se trata da 'viagem filosófica': o naturalista e a sua equipe.

\section{REFERÊNCIAS}

Abreu, J. L. N. (2007). A colônia enferma e a saúde dos povos: A medicina das 'luzes' e as informações sobre as enfermidades da América portuguesa. História, Ciência Saúde: Manguinhos, 14(3), 761-778. https://doi.org/10.1590/S010459702007000300005
Annaes da Bibliotheca Nacional do Rio de Janeiro. (1876-1877 [1876]). Vol. 1. Typ. G. Leuzinger \& Filhos. http://memoria. bn.br/pdf/402630/per402630_1876_00001.pdf

Annaes da Bibliotheca Nacional do Rio de Janeiro. (1876-1877 [1877]). Vol. 2(1). Typ. G. Leuzinger \& Filhos. http://memoria. bn.br/pdf/402630/per402630_1876_A00002.pdf

Annaes da Bibliotheca Nacional do Rio de Janeiro. (1877-1878 [1878]). Vol. 3. Typ. G. Leuzinger \& Filhos. http://memoria. bn.br/pdf/402630/per402630_1877_A00003.pdf

Antunes, A. P., Massarani, L., \& Moreira, I. C. (2019). Practical botanists and zoologists: Contributions of Amazonian natives to natural history expeditions (1846-1865). Historia Crítica, (73), 137-160.

Areia, M. L. R, Miranda, M. A., \& Hartman, T. (1991). Memória da Amazónia: Alexandre Rodrigues Ferreira e a viagem philosophica pelas capitanias do Grão-Pará, Rio Negro, Mato Grosso e Cuiabá. Universidade de Coimbra.

Areia, M. L. R., Miranda, M. A., \& Martins, M. R. (2013). Diáspora e redescoberta das colecções de Alexandre Rodrigues Ferreira. In C. Fiolhais, C. Simões \& D. Martins (Eds.), História da Ciência luso-brasileira: Coimbra entre Portugal e o Brasil (pp. 157-168). Imprensa da Universidade de Coimbra.

Barrera-Osorio, A. (2008). Empiricism in the Spanish Atlantic world. In J. Delbourgo \& N. Dew (Eds.), Science and empire in the Atlantic world (pp. 177-202). Routledge.

Barrera-Osorio, A. (2010). Experts, nature and the making of Atlantic empiricism. Osiris, 25(1), 129-148. https://doi. org/10.1086/657266

Biblioteca Digital Luso-Brasileira. (n.d.). https://bdlb.bn.gov.br/ acervo/browse? value $=$ Ferreira\%2C + Alexandre + Rodrigu es\%2C+1756-1815+-+ Correspondence\&type = subject

Brasiliana Iconográfica. (n.d.). https://www.brasilianaiconografica.art. br/artigos/20106/colecao-alexandre-rodrigues-ferreira

Biblioteca Nacional Digital. (n.d.). http://bndigital.bn.br/projetos/ alexandre/Index.html

Brigola, J. C. P. (2004). Viagem, ciência e administração no Brasil colonial - os gabinetes setecentistas de história natural de Luís Pinto de Balsemão, de Luís de Vasconcelos e Sousa e de Luís de Albuquerque Cáceres. In Estudos de homenagem a Luís António de Oliveira Ramos (pp. 331-339). Faculdade de Letras da Universidade do Porto.

\footnotetext{
12 A proposta é de Mignolo (2002, p. 67), quando se refere a uma "relocation of the thinking and a critical awareness of the geopolitics of knowledge".
}

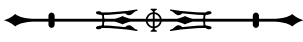


Cabral, A. V. (1952). Alexandre Rodrigues Ferreira: Notícia das obras manuscritas e inéditas relativas à viagem filosófica do dr. Alexandre Rodrigues Ferreira pelas capitanias do GrãoPará, Rio Negro, Mato Grosso e Cuiabá (1783-93). In Anais da Biblioteca Nacional (Vol. 72, pp. 37-151). Departamento de Imprensa Nacional.

Campos, R. (2015). Ciencia y control imperial en el Mato Grosso português. Revista Digital de Historia y Arqueologia desde el Caribe Colombiano, (25), 34-71.

Candiani, V. S. (2017). Reframing knowledge in colonization: Plebeians and municipalities in the environmental expertise of the Spanish Atlantic. History of Science, 55(2), 234-252. https://doi.org/10.1177/0073275317706041

Cantinho, M. (2010). Colecções etnográficas extra-ocidentais em Portugal: Passado, presente e futuro. In Congresso Ibérico de Estudos Africanos. https://repositorio.iscte-iul. pt/bitstream/10071/2200/1/CIEA7_1_CANTINHO,\%20 Colec\%C3\%A7\%C3\%B5es\%20etnogr\%C3\%A1ficas\%20 extra-ocidentais\%20em\%20Portugal.pdf

Carapito, S. T. O. M. (2014). As moléculas da cor: Nas máscaras da viagem filosófica (1783-1792) e num tecido oriental (1880) [Dissertação de mestrado, Universidade de Coimbra, Coimbra, Portugal].

Cardoso, J. L. (n.d.). Vandelli: A História natural ao serviço de uma estratégia económica. Ciência em Portugal Personagens e Episódios. http://cvc.instituto-camoes.pt/ciencia/e65.html

Carvalho, J. L. F. (1855). Memórias da vida de José Liberato Freire de Carvalho. Tipographia de José Baptista Morando.

Carvalho, R. (2000). O material etnográfico do Museu Maynense da Academia de Ciências de Lisboa. ACL.

Carvalho Júnior, A. D. (2000). Do índio imaginado ao índio inexistente. (A construção da imagem do índio na viagem filosófica de Alexandre Rodrigues Ferreira) [Dissertação de mestrado, UNICAMP, Campinas].

Carvalho Júnior, A. D., \& Noronha, N. M. (Orgs.). (2011). A Amazónia dos viajantes: História e ciência. Editora da Universidade Federal do Amazonas.

Casaleiro, P. J. E., \& Pereira, H. M. (2018). A exposição natureza exótica: Aspectos do acervo de Alexandre Rodrigues Ferreira na Universidade de Coimbra. Agricultura Familiar: Pesquisa, Formação e Desenvolvimento, 12(1), 111-130. http://dx.doi. org/10.18542/raf.v12i1.6081

Coelho, M. C. (2000). A civilização da Amazônia - Alexandre Rodrigues Ferreira e o Diretório dos índios: A educação de indígenas e luso-brasileiros pela ótica do trabalho. Revista de História Regional, 5(2), 149-174.

Correia Filho, V. (1939). Alexandre Rodrigues Ferreira: Vida e obra do grande naturalista brasileiro. Companhia Editora Nacional.
Costa, M. F. (2001). Alexandre Rodrigues Ferreira e a capitania de Mato Grosso: Imagens do interior. História, Ciências, Saúde - Manguinhos, 8, 993-1014. https://doi.org/10.1590/S010459702001000500011

Costa, M. F., \& Diener, P. (2010). Amarguras de una expedición: El viaje filosófico de Rodrigues Ferreira a la América Portuguesa. In R. S. Baeza (Ed.), Ciencia-mundo: Orden republicano, arte y nación en América (pp. 67-96). Centro de Investigaciones Diego Barros Arana de la DDIBAM.

Cunha, O. R. (1991). O naturalista Alexandre Rodrigues Ferreira: Uma análise comparativa de sua viagem filosófica (1783-1793) pela Amazônia e Mato Grosso com a de outros naturalistas posteriores. Museu Paraense Emílio Goeldi.

Davids, K. (2014). The scholarly Atlantic: Circuits of knowledge between Britain, the Republic and the Americas in the eighteenth century. In G. Oostindie \& J. V. Roitman (Eds.), Dutch Atlantic Connections, 1680-1800 (pp. 224-248). Brill.

Dias, J. R. (Coord.). (1992). Brasil: Nas vésperas do mundo moderno. Comissão Nacional para as Comemorações dos Descobrimentos Portugueses.

Domingues, Â. (1991). Viagens de exploração geográfica na Amazónia em finais do século XVIII: Política, ciência e aventura. Centro de Estudos de História do Atlântico.

Domingues, Â. (1992). Um novo conceito de ciência ao serviço da Razão de Estado: A viagem de Alexandre Rodrigues Ferreira ao Norte brasileiro. In Anais da Academia da Marinha (pp. 17-32). Academia da Marinha.

Domingues, Â. (2011). "Desde Piso e Marcgrave que ninguém com curiosidade tolerável descreveu a natureza brasileira": Os relatos de Cook, Banks e Parkinson e a construção de imagens do Brasil colonial. Revista Almanack, (1), 35-51. https://doi. org/10.1590/2236-463320110104

Domingues, Â. (2019). Museus, coleccionismo e viagens científicas em Portugal de finais de setecentos. Asclepio: Revista de Historia de la Medicina y de la Ciencia, 71(2), 1-19. https://doi. org/10.3989/asclepio.2019.12

Domingues, Â., \& Alves-Melo, P. (2021). Iluminismo no mundo luso-brasileiro: um olhar sobre a Viagem Filosófica à Amazônia, 1783-1792. Ler História, 78, 157-178. https://doi.org/10.4000/ lerhistoria.7879

Equipe da Biblioteca Nacional. (n.d.). Coleção Alexandre Rodrigues Ferreira. Brasiliana Iconografia. https://www. brasilianaiconografica.art.br/artigos/20106/colecao-alexandrerodrigues-ferreira

Falcão, E. C. (1970). Breve notícia sobre a "viagem filosófica" de Alexandre Rodrigues Ferreira (1783-1792). Revista de História, 40(81), 185-195. 
Faria, M. F. (2001). A imagem útil. José Joaquim Freire (1760-1847) desenhador topógrafo e de história natural. UAL.

Felismino, D. (2014). Saberes, natureza e poder. Colecções científicas da antiga Casa Real Portuguesa. Museus da Universidade de Lisboa.

Ferreira, A. R. (1841). Propriedade e posse das terras do Cabo do Norte pela coroa de Portugal. Revista do Instituto Histórico e Geográfico Brasileiro, tomo 3, 389-421. https://drive. google.com/file/d/0B_G9pg7CxKSseS13dWdnY29Oc2s/ view? resourcekey $=0-\bar{H} 34 D B Y s U U U 5 w H D 1 z W r N c Q$

Ferreira, A. R. (1849). Viagem à gruta das Onças. Revista do Instituto Histórico e Geográfico Brasileiro, tomo 12, 87-95. https://drive. google.com/file/d/OB_G9pg7CxKSsMjBCWDIFbmo2Zm8/ view? resourcekey $=0-\bar{b} A A S 5 \mathrm{kLjz3S5RWmjvNw8Ag}$

Ferreira, A. R. (1863). Gruta do Inferno. Descrição feita pelo Dr. Alexandre Rodrigues Ferreira, em Cuiabá (1789). Revista do Instituto Histórico e Geográfico Brasileiro, 4, 363-367.

Ferreira, A. R. (1885). Diário da viagem filosófica ao Rio Negro [Pt. 1]. Revista do Instituto Histórico e Geográfico Brasileiro, 48(70), $1-234$.

Ferreira, A. R. (1886). Diário da viagem filosófica ao Rio Negro [Pt. 1]. Revista do Instituto Histórico e Geográfico Brasileiro, 49(72), 123-288.

Ferreira, A. R. (1887). Diário da viagem filosófica ao Rio Negro [Pt. 2]. Revista do Instituto Histórico e Geográfico Brasileiro, 50(75), $11-141$.

Ferreira, A. R. (1888). Diário da viagem filosófica ao Rio Negro [Pt. 1]. Revista do Instituto Histórico e Geográfico Brasileiro, 51(76), 5-166.

Ferreira, A. R. (1971). Viagem filosófica (Iconografia, Vol. 1). Conselho Federal de Cultura.

Ferreira, A. R. (1972). Viagem filosófica: Memórias (Zoologia e botânica). Conselho Federal de Cultura.

Ferreira, A. R. (1974). Viagem filosófica: Memórias (Antropologia). Rio de Janeiro: Conselho Federal de Cultura.

Ferreira, A. R. (1983). Viagem filosófica ao Rio Negro. Museu Paraense Emílio Goeldi.

Ferreira, A. R. (2007a). História filosófica e política do rio da Madeira. In J. P. M. Soares \& C. Ferrão (Orgs.), Viagem ao Brasil de Alexandre Rodrigues Ferreira (Vol. III, pp. 11-13). Kapa Editorial.

Ferreira, A. R. (2007b). Viagem filosófica ao Rio Negro. In F. J. Santos, A. S. Ugarte \& M. C. Oliveira (Orgs.), Viagem filosófica ao Rio Negro (pp. 564-571). Editora da Universidade Federal do Amazonas.

Goeldi, E. A. (1895). Dr. Alexandre R. Ferreira: Mormente em relação às suas viagens na Amazônia e sua importância como naturalista. Alfredo Silva \& Companhia.
Guedes, I. C. (2013). A expedição filosófica ao Brasil de Alexandre Rodrigues Ferreira: Carácter administrativo e estratégico no vale o rio Branco [Trabalho de conclusão de curso, Universidade Federal de Roraima, Boa Vista].

Herbário de Alexandre Rodrigues Ferreira (sec. XVIII-XIX). (n.d.). http://memoria.ul.pt/index.php/Herb\%C3\%A1rio_de Alexandre_Rodrigues_Ferreira_(s\%C3\%A9c._XVIII-XIX

Kantor, I. (2004). Ciência e império: Trajetórias de ilustrados lusoamericanos na segunda metade do século XVIII. In Laboratório do mundo: Ideias e saberes do século XVIII (pp. 245-252). Governo do Estado de S. Paulo e Pinacoteca do Estado.

Lamarca, E. T. (2015). Alexandre Rodrigues Ferreira e sua viagem filosófica ao Rio Negro [Dissertação de mestrado, Universidade de São Paulo, São Paulo].

Lopes, A. R. (1998). Alexandre Rodrigues Ferreira e a viagem filosófica: Economia e ciência na Amazônia colonial [Dissertação de mestrado, Universidade Federal do Paraná, Curitiba].

Manning, P. (2016). Introduction. Building global perspectives in history of science: The era from 1750 to 1850 . In P. Manning \& D. Rood (Eds.), Global science practice in an Age of revolutions, 1750-1850 (pp. 1-8). University of Pittsburgh Press.

McOuat, G. (2017). Global scientific practice in an age of Revolutions 1750-1850. Journal of Interdisciplinary History, 48(1), 81-83. https://doi.org/10.1162/JINH_r_01093

Mignolo, W. D. (2002). The geopolitics of knowledge and the colonial difference. The South Atlantic Quarterly, 101(1), 57-95. https://doi.org/10.1215/00382876-101-1-57

Munteal Filho, O. (2006). Académicos e letrados na crise do Antigo Regime luso-brasileiro - século XVIII. Intellèctus, 5(1), 1-23.

Murphy, K. S. (2011). Translating the vernacular: Indigenous and African knowledge in the eighteenth-century British Atlantic. Atlantic Studies, 8(1), 29-48. https://doi.org/10.1080/147888 10.2011.541188

Museu Maynense. (2016). http://www.acad-ciencias.pt/academia/ museu-sala-brasil

Museu Nacional de História Natural e da Ciência. (n.d.). http://digital. museus.ul.pt/items/browse? collection $=45$

Oliveira, P. P. (2008). Alexandre Rodrigues Ferreira e seus estudos das plantas do norte e centro-oeste do Brasil [Dissertação de mestrado, Universidade Católica de São Paulo, São Paulo].

Oliveira, T. K. (2018). La expedición filosófica de Alexandre Rodrigues Ferreira. Boletin de la Sociedad Geográfica Española, (60). https://sge.org/publicaciones/numero-de-boletin/boletin-60/ expedicion-filosofica-alexandre-rodrigues-ferreira/ 
Pataca, E. M. (2001). Arte, ciência e técnica na viagem fhilosofhica de Alexandre Rodrigues Ferreira: A confeção e utilização de imagens histórico-geográficas na capitania do Grão-Pará entre setembro de 1783 a outubro de 1784 [Dissertação de mestrado, Universidade Estadual de Campinas, Campinas].

Pataca, E. M. (2005). A ilha do Marajó na viagem philosophica (17831792) de Alexandre Rodrigues Ferreira. Boletim do Museu Paraense Emílio Goeldi. Série Ciências Humanas, 1(1), 149-169.

Pataca, E. M. (2006). Terra, água e ar nas viagens científicas portuguesas (1755-1808) [Tese de doutorado, Universidade Estadual de Campinas, Campinas].

Pataca, E. M. (2015). Mobilidades e permanências de viajantes no Mundo Português: Entre práticas e representações científicas e artísticas [Tese de livre-docência, Universidade de São Paulo, São Paulo]

Pataca, E. M. (2018). Entre a engenharia militar e a arquitetura médica: Representações de Alexandre Rodrigues Ferreira sobre a cidade de Belém no final do século XVIII. História, Ciências, Saúde: Manguinhos, 25(1), 89-113. https://doi. org/10.1590/s0104-59702018000100006

Pontes, R. S. S. (1840). Dr. Alexandre Rodrigues Ferreira. Revista do Instituto Histórico e Geográfico Brasileiro, 2, 499-502.

Raminelli, R. (1998). Ciência e colonização: Viagem filosófica de Alexandre Rodrigues Ferreira. Tempo, 6(19), 157-182.

Raminelli, R. (2009). Viagens ultramarinas: Monarcas, vassalos e governo à distância. Alameda.

Raminelli, R., \& Silva, B. (2014). Teorias e imagens antropológicas na viagem filosófica de Alexandre Rodrigues Ferreira (17831792). Boletim do Museu Paraense Emílio Goeldi. Ciências Humanas, 9(2), 323-342. https://doi.org/10.1590/198181222014000200005

Reis, A. C. F. (1971). Prefácio. In A. R. Ferreira (Ed.), Viagem filosófica (Iconografia, Vol. 1). Conselho Federal de Cultura.

Rodrigues, B. G. (2017). Índios em Portugal: Perspetivas a partir de coleções e exposições museológicas posteriores à Constituição brasileira de 1988 [Dissertação de mestrado, Universidade de Lisboa, Lisboa].

Rodrigues, S. R. S. (2010). Alexandre Rodrigues Ferreira e a preservação do seu acervo na Biblioteca Nacional [Monografia de especialização, Museu de Astromia e Ciências Afins, Rio de Janeiro].

Rodríguez García, M. E. (2015). Longe do gabinete: Viagens científicas à América portuguesa e espanhola (1777-1792) e representação da natureza. Revista Digital de Historia y Arqueologia desde el Caribe Colombiano, 11(25), 144-177.
Sá, M. J. M. C. (1838, agosto 22). Parecer relativo aos papéis de Alexandre Rodrigues Ferreira. (21, 1, 047, No. 008, doc. 14). Fundação Biblioteca Nacional, Rio de Janeiro.

Sá, M. J. M. C. (1840). Additamento. Revista do Instituto Histórico e Geográfico Brasileiro, 2, 510-513.

Safier, N. (2007). Every day that I travel... is a page that I turn: Reading and observing in eighteenth-century Amazonia. Huntington Library Quarterly, 70(1), 103-128. https://doi. org/10.1525/hlq.2007.70.1.103

Sala Catalá, J. (1992). La ciencia en las expediciones de límites hispano-portuguesas: Su proyección internacional. Acta Hispanica ad Medicinae Scientianrumque Historiam Ilustrandam, 12, 23-33.

Sánchez, A. (2019). The "empirical turn" in the historiography of the Iberian and Atlantic science in the early modern world: From cosmography and navigation to ethnography, natural history, and medicine. Tapuya: Latin American Science, Technology and Society, 2(1), 317-334. https://doi.org/10.1080/25729861.2 019.1631684

Sanjad, N. (2007). As fronteiras do Ultramar: Engenheiros, matemáticos, naturalistas e artistas na Amazônia, 1750-1820. https://www. cepese.pt/portal/pt/publicacoes/obras/artistas-e-artifices-esua-mobilidade-no-mundo-de-expressao-portuguesa/asfronteiras-do-ultramar-engenheiros-matematicos-naturalistase-artistas-na-amazonia-1750-1820

Schaffer, S., Roberts, L., Raj, K., \& Delbourgo, J. (Eds.). (2009). The brokered world: Go-betweens and global intelligence, 1770-1820. Science History Publications.

Silva, B. (2013). (Re)conhecendo impérios: Viagens filosóficas a serviço das coroas europeias e as formas de classificação do homem americano na segunda metade do século XVIII. Revista 7 Mares, (3), 22-27.

Silva, J. P. (1994). Pressupostos metodológicos para uma edição crítica da obra de Alexandre Rodrigues Ferreira. IV Encontro Internacional de pesquisadores do manuscrito e de edições, Annablume, São Paulo. http://www.filologia.org.br/pereira/ textos/index.htm

Silva, J. P. (2006). Viagem ao Brasil de Alexandre Rodrigues Ferreira. SOLETRAS, (11), 131-143.

Simon, W. J. (1983). Scientific expeditions in the Portuguese overseas territories (1783-1808) and the role of Lisbon in the intellectualscientific community of the late eighteenth century. Instituto de Investigação Cientíica Tropical.

Sodré, M. (n.d.). Sobre Alexandre Rodrigues Ferreira. https://bndigital. bn.gov.br/dossies/alexandre-rodrigues-ferreira/ 
Tapadas, S. E. T. A. (2006). Desenho de História Natural: Análise comparada de desenhos de animais produzidos nas viagens ao Brasil de frei Cristóvão de Lisboa (século XVII) e do dr. Alexandre Rodrigues Ferreira (séc. XVIII) [Dissertação de mestrado, Universidade de Lisboa, Lisboa].

Tavares, H. M. (2014). Sobre o céu, a terra, a água e o ar: Representações de viajantes ilustrados sobre a Amazônia entre 1735 e 1815 [ese de doutorado, Universidade Federal do Paraná, Curitiba].
Verran, R. S. (2006). Inventário científico do Brasil no século XVIII: A contribuição de Alexandre Rodrigues Ferreira para o conhecimento da natureza e dos índios [Tese de doutorado, Pontifícia Universidade do Rio Grande do Sul, Porto Alegre].

Wendt, H. (Ed.). (2016). The globalization of knowledge in the Iberian colonial world. Max Planck Institute for the History of Science. 